\title{
Vulvar Dysesthesia: New Treatments for a Real Therapeutic Challenge
}

\author{
C. Rodríguez-Cerdeira ${ }^{*}, 1$, A. Guerra-Tapia ${ }^{2}$, G. Bravo ${ }^{3}$, M.J. Álvarez ${ }^{4}$ and P. Pérez-Villaverde ${ }^{5}$ \\ ${ }^{I}$ Department of Dermatology, Complejo Hospitalario de Vigo \& University of Vigo, Vigo, Spain \\ ${ }^{2}$ Department of Dermatology, Hospital Doce de Octubre, Madrid, Spain \\ ${ }^{3}$ Department of Gynaecology, Complejo Hospitalario de Vigo, Vigo, Spain \\ ${ }^{4}$ Department of Plastic Surgery, Private practice, Lugo, Spain \\ ${ }^{5}$ Department of Psychology, Instituto de Medicina Técnica, Vigo, Spain
}

\begin{abstract}
The syndrome of chronic vulvar pain, which is traditionally referred to as vulvodynia, but is nowadays called either local or general vulvar dysesthesia, continues to be enigmatic for doctors involved in its diagnosis and treatment. Most patients suffering from local dysesthesia or vestibulitis have undergone multiple local or systemic treatments, generally unsuccessfully, which makes them visit various gynaecologists, dermatologists and even psychiatrists. Pain combined with the repeated therapeutic failures provoke a feeling of frustration and abandonment which end up with personal repercussions in the life of the patient and his relationship with his partner. This, combined with the conviction of the patient that no ideal treatment exists, converts this affection into a therapeutic challenge for the doctor who tries to treat it.

We present the results obtained for 5 patients diagnosed of local vulvar dysesthesia or vestibulitis, previously unsuccessfully treated with combined therapies, who favourably responded to repeated injections of Botulinum toxin A (Vistabel ${ }^{\circledR}$, Allegran, Europe). The dose ranged between 24 and $48 \mathrm{U}$, administered every 90 days in the case of persistence of the symptoms. The main visual analogue pain score was 3.4 after the $1^{\text {st }}$ dose of the Botulinum toxin A; it was 9.8 before the treatment. None of the patients had recurrence during the one to two years and a half, average 17 months, follow-up period. Botulinum toxin A is effective in blocking nociception. It is a safe and effective therapy for the treatment of vulvar dysesthesia of muscular or neuroinflammatory origin.
\end{abstract}

Keywords: Dysesthesia vulvar, vestibulitis, sexual pain, Botulinum toxin A.

\section{INTRODUCTION}

Vulvar dysesthesia is a complicated syndrome which has been attributed with having a multifactorial origin. Two types of vulvodynia are clinically distinguished: local vulvar dysesthesia or local vestibulitis in the area of the vulvar vestibule, and generalized vulvar dysesthesia or dysesthetic vulvodynia, in which pain diffusely affects a wide area of the vulva [1]. No standard treatment exists, although there are multiple options, as may be observed in the bibliography, from topical or systemic treatments to surgical treatments, some of which have systemic side effects or produce alterations in sexual behaviour. Recently the introduction of Botulinum toxin $\mathrm{A}$, which has been extensively used as a muscular paralyser for certain types of chronic pain, and which, moreover, does not produce significant side effects, opens 73a new window to the treatment of this pathology [2].

In this study we present 5 new cases of patients suffering from vulvar dysesthesia or vestibulitis which proved refractory to conventional treatments but which responded well to treatment with Botulinum toxin A.

*Address correspondence to this author at the Department of Dermatology, CHUVI, Meixoeiro Hospital \& University of Vigo, 36200, Vigo, Galicia, Spain; Tel: 0034600536114; Fax: 0034986276416;

E-mail: Carmen.Rodriguez.Cerdeira@sergas.es; aristoteles_cerdeira@yahoo.es

\section{MATERIALS AND METHODS}

We have included 5 patients whose ages ranged between 35 and 58 years with an average age of 46 years old. All patients underwent a detailed clinical review which included gynaecologic-obstetric history, sexual history, in which they were asked at what age they began sexual relations, existence of sexual abuse, stable, casual or inexistent sexual partner and attitude with their partner. Special attention was paid to the location and characteristics of the pain. History of sexually transmitted infections were evaluated. With respect to the gynaecological exploration special interest was paid to the colposcope of the cervix, vagina and vulva. The vaginal $\mathrm{pH}$ was also evaluated. We carried out cultures of vaginal smears and urine of all the patients. A haemogram and complete biochemical, immunological and serological analyses were also requested, as well as detection of parasites and faeces culture. Finally the area of hypersensitivity was marked using the cotton-pal technique. The study was completed by carrying out patch tests and Schirmer's test, and also biopsies in three of the cases. All the patients were diagnosed as suffering from local vulvar dysesthesia or vestibulitis. All the patients had been previously treated with combined therapy which had proven unsuccessful, as shown in Table 1. All the patients received additional support from a gynaecologist, psychologist and psychiatrist. 
Table 1.

\begin{tabular}{|c|c|c|c|c|c|c|}
\hline $\mathbf{N}^{0}$ & $\begin{array}{c}\text { Socioeconomic Status/ } \\
\text { Marital Status }\end{array}$ & Age & Hormonal Factors & $\begin{array}{l}\text { Hormonal } \\
\text { Treatments }\end{array}$ & Previous Treatments & $\begin{array}{c}\text { Duration } \\
\text { of Pain }\end{array}$ \\
\hline 1 & Higher/Married & 35 & Premenopause & $\begin{array}{l}\text { Contraceptives } \\
\text { from } 17 \text { years old }\end{array}$ & $\begin{array}{c}\text { Analgesics, AINSD, tricyclic antide- } \\
\text { pressants, local anaesthetics locales } \\
\text { biofeedback }\end{array}$ & 2 year \\
\hline 2 & Higher/Married & 43 & Surgically induced menopause & - & $\begin{array}{l}\text { Analgesics, AINSD, tricyclic antide- } \\
\text { pressants, local anaesthetics and oral } \\
\text { calcium citrate }\end{array}$ & 1 year \\
\hline 3 & Higher/Married & 32 & Premenopause & $\begin{array}{l}\text { Contraceptives } \\
\text { from } 19 \text { years old }\end{array}$ & $\begin{array}{c}\text { Analgesics, AINSD, tricyclic antide- } \\
\text { pressants, local anaesthetics, oral cal- } \\
\text { cium citrate, } \alpha \text {-interferon injections and } \\
\text { biofeedback }\end{array}$ & 1 year \\
\hline 4 & Higher/Married & 56 & Menopause & $\begin{array}{l}\text { HRT (oestrogen }+ \\
\text { progesterone) }\end{array}$ & $\begin{array}{l}\text { Analgesics, AINSD, tricyclic antide- } \\
\text { pressants, local anaesthetics, oral cal- } \\
\text { cium citrate, } \alpha \text {-interferon injections, } \\
\text { biofeedback and acupuncture }\end{array}$ & 2 year \\
\hline 5 & Higher/Married & 58 & Menopause & $\begin{array}{l}\text { HRT (conjugated } \\
\text { oestrogen) }\end{array}$ & $\begin{array}{l}\text { Analgesics, AINSD, tricycle antidepres- } \\
\text { sants, local anaesthetics, } \alpha \text {-interferon } \\
\text { injections and biofeedback }\end{array}$ & 1 year \\
\hline
\end{tabular}

Treatment administered, after receiving informed consent, was to use reconstructed Botulinum toxin A (Vistabel ${ }^{\circledR}$ ) $(50 \mathrm{U} / 1.25 \mathrm{ml}, 100 \mathrm{U} / 2.5 \mathrm{ml})$ using a sterile 30 gauge needle. Injections were carried out in the vestibule, at three points which were separated by $1 \mathrm{~cm}$. At each of the three injection points $0.2 \mathrm{ml}(8 \mathrm{U})$ of Botulinum toxin A was administered to reach a dose of $24 \mathrm{U}$ (Table 2). The remaining U's of Botulinum toxin A were used in patients for cosmetic reasons for the correction of facial wrinkles, where, in this case, the dose per injection site was $0.1 \mathrm{ml}$. A dose of 500 $\mathrm{mg}$ azitromycin was prophylactically administered for three days starting from the first day of injection. The patients were evaluated again at 15, 30 and 90 days. If symptoms persisted, they were injected in the same places as before but duplicating the dose until a total of $48 \mathrm{U}$. All the patients were tested using the visual analogue scale (VAS) immediately before the treatment and 15 days after giving each dose of the treatment (Table 2).

\section{RESULTS}

Dyspareunia was a constant symptom in all cases. It was accompanied by vulvar pain and even vaginism in some cases. The latter intensified the pain and so made sexual relationships more difficult. All this caused obstacles for interpersonal relationships and psychopathological disorders.
In all the patients we observed painful gynaecological explorations which were sometimes impossible. All the patients had been suffering from pain for a year or more. All the patients reported vestibular pain and in the majority $(80 \%)$ the pain was located in the posterior part of the vestibule and/or the urethra (20\%). There were antecedents in $40 \%$ of the patients of early and continued use of oral contraceptives, with the patients starting to take them at 17 and 19 years respectively. All the patients had been treated with combined regimes using the different medical treatments available on the market. Three of the patients $(60 \%)$ had received earlier treatment with $\alpha$-interferon and one (20\%) with acupuncture. None of the patients had been surgically treated (Table 1). The patients were reviewed at 15, 30 and 90 days. Pain evaluation by a VAS questionnaire was carried out before treatment on the fifteenth day. The main visual analogue pain score was 3.4 after the first injection; it had been 9.8 before the treatment. We did not observe recurrence during the follow-up period of up to 2 years after ending the treatment. In the case of requiring a new dose, this was prescribed in the third visit ( 90 days). The revision schedule for successive doses was analogue to that carried out during the first visit. New doses were not given when there was remission or a great reduction in symptoms. Three of the patients $(60 \%)$ improved considerably after the first dose of Botulinum toxin A. Two patients required a second dose (40\%).

Table 2.

\begin{tabular}{|c|c|c|c|c|c|}
\hline $\mathbf{N}^{o}$ & Injection Site & $\begin{array}{c}\text { Injection Dose } \\
\left(1^{\text {st }} / 2^{\text {nd }} / 3^{\text {th }}, U\right)\end{array}$ & $\begin{array}{l}\text { Pain Score }\left(V_{A S}{ }^{1}\right) \\
\text { Pre/Post }\left(1^{\text {st }}\right) \text { Dose }\end{array}$ & $\begin{array}{l}\text { Pain Score }\left(V_{A S}^{1}\right) \\
\text { Pre/Post }\left(2^{\text {nd }}\right) \text { Dose }\end{array}$ & $\begin{array}{l}\text { Pain Score }\left(\mathrm{VAS}^{1}\right) \\
\text { Pre/Post }\left(3^{\text {th }}\right) \text { Dose }\end{array}$ \\
\hline 1 & Vestibule & $24 / 48$ & $10 / 1$ & - & - \\
\hline 2 & Vestibule & $24 / 48$ & $10 / 7$ & $7 / 1$ & - \\
\hline 3 & Vestibule & 24 & $9 / 1$ & - & - \\
\hline 4 & Vestibule & $24 / 48 / 48$ & $10 / 7$ & $7 / 6$ & $6 / 1$ \\
\hline 5 & Vestibule & 24 & $10 / 1$ & - & - \\
\hline
\end{tabular}


The main visual analogue pain score was 3.5 after the first injection; it had been 7 before the treatment. One of them $(20 \%)$, required a third one. The main visual analogue pain score was 1 after the first injection; it had been 6 before the treatment (Table 2).

None of the patients showed bleeding, infection, muscle paralysis, voiding difficulty, bowel problems, nausea or flulike symptoms. All the patients acknowledged that the pain had disappeared or decreased considerably after completing the treatment. They also reported improvement in their sexual relationships, with an absence of discomfort or pain during sexual relations. Only one patient reported a reduction in the intensity of orgasms after treatment.

\section{DISCUSSION}

Vulvodynia is a chronic pathology, although it may sometimes have an acute onset. The term was introduced in 1983 by the International Society for the Study of Vulvar Disease (ISSDV) [3] to define clinical discomforts such as burning, stinging, irritation, itching and pain, highlighting the absence of pruritus and other clinical findings which could explain the symptoms. Recently the same group gave the name vulvar dysesthesia as they considered this term to be more appropriate. This group also suggests that the pain is of neuropathic origin [4]. The most related involvement is: dermatosis, early and prolonged use of contraceptives [5], recurrent candidiasis, infection by human papillomavirus (HPV), trauma, abrasive therapies, neoplasias [6], psychological affections.

In local vulvar dysesthesia or vestibulitis, the pain is strictly referred to the vulvar vestibule. The diagnosis is based on the criteria of Friedrich from 1987 [7], among which are included: intense pain on palpitation of the vestibular region or on vaginal penetration, hypersensitivity or pain on pressure to the vestibular region, vestibular rash, dyspareunia and intense sharp pain produced by palpitation with a cotton swab in the vestibule, which is known as the cotton-pal test. Apart from the complementary tests already described as being necessary to reach a correct diagnosis [8], in our patients no complementary test orientated us towards a diagnosis different from vulvar dysesthesia or vestibulitis. On physical examination the patients were seen to have normal external genitals or with a slight rash. Although no standard treatment exists among those published by various authors we can cite: general advice, symptomatic treatment with creams, local anaesthetics and lubricants. Besides treatments with oral antimycotics, pain killers, tricyclic antidepressants, anticonvulsives, biofeedback electro-myograph, surgical treatment and psychotherapy. It is recommended to begin with the simplest therapy $[9,10]$. These varied responses to such diverse therapies underscore the lack of knowledge surrounding vulvar pain, and further research in this area is certainly needed. Approximately $15 \%$ of women have chronic dyspareunia that is poorly understood, infrequently cured, often highly problematic, and distressing [9]. Although the real ethiology of vulvar dysesthesia is not clear, the latest hypotheses point to neuropathic pain.
The effect of Botulinum toxin A on dyspareunia may be explained through neurotransmission blocks at the nociceptive receptors, which are distributed in the submucosal layers of the vestibule. This mechanism may also explain the use of Botulinum toxin A in interstitial cystitis [11].

Recently various papers have been published in the literature on the use of Botulinum toxin A in the treatment of vulvar dysesthesia and genital pain syndromes [12-16]. Botulinum toxin A produces an irreversible synaptic blockade at the neuromuscular end plates, resulting in muscle paralysis. Improvement of pain, however, might not always coincide with or be in proportion to the degree of muscular paralysis. It is known that during chronic inflammatory states and pain the efferent functions of the sensory nerves play an important role in sensitizing afferent nerve terminals to peripheral stimuli $[11,16]$. The effect of Botulinum toxin A may be based on the neuronal uptake of the Botulinum toxin A or its metabolites in the peripheral or central nociceptive receptors. Besides, alterations in the secretion of neurotransmitters and neuropeptides, including inhibition of substance $\mathrm{P}$ release, caused by botulinum toxin A may contribute to the reduction of pain [16].

In this study, we only included five patients, which is a relatively low number of patients enrolled, although there are not any series of higher numbers in the literature. In this study we did not use placebo/blinding. To measure the level of pain we used only the VAS. In future investigations we shall improve our data forming process to compare results. In our present study we observed positive results in the management of dyspareunia and pain in patients with vulvar dysesthesia. The patients continued for between one and two years without having any published adverse effects with Botulinum toxin A, so, although this is a preliminary study, we can conclude by saying that Botulinum toxin A is a new, safe and effective treatment option for vulvar dysesthesia.

\section{REFERENCES}

[1] Bohm-Starke N, Hilliges M, Brodda-Jansen G, Falconer C, Rylander E, Torebjörk E. Increased intraepithelial innervations in women with vulvar vestibulitis syndrome. Pain 2001; 94: 177-83.

[2] Arezzo JC. Possible mechanisms for the effects of botulinum toxin on pain. Clin J Pain 2002; 18: S125-132.

[3] Selected ISSVD (International Society for the Study of Vulvar Disease). J Reprod Med 1986; 31: 975-8.

[4] Moyal-Barracco M, Lynch PJ. 2003 ISSDV terminology and classification of vulvodinia: a historical perspective. J Reprod Med 2004; 49: 772-7.

[5] Greenstein A, Ben-Aroya Z, Fass O, Militscher I, Roslik Y, Chen J, Abramov L. Vulvar vestibulitis syndrome and estrogen dose of oral contraceptive pills. J Sex Med 2007; 4: 1679-83.

[6] Rodríguez-Cerdeira C, de Argila D, A Guerra. Tumores malignos. En: Guerra Tapia A, editora. Manual y atlas de las enfermedades de la vulva. Barcelona: Glosa; 2006. pp. 261-83.

[7] Friedich SG. Vulvar vestibulitis syndrome. J Reprod Med 1987; 32: 110-14.

[8] Margesson LJ, Moyal-Barracco M, Piper C, Reed BD, Stewart EG, WikinsonEJ. The vulvodinia guideline. J Lower Genital Tract Dis 2005; 9: 40-51.

[9] Weijmar Schultz W, Basson R, Binik Y, Eschenbach D, Wesselmann U, Van Lankveld J. Women's sexual pain and its management. J Sex Med 2005; 2: 301-16. 
[10] Hoffstetter S, Leong FC, LeFevre C. Vulvodynia. Mo Med 2007; 104: 522-5.

[11] Yoon H, Chung WS, Shim BS. Botulinum toxin A for the management of vulvodynia. Int J Impot Res 2007; 19: 84-7.

[12] Bennani B, Raki S, Monnier G, Pelletier F, Humbert P. Botulinum toxin for vulvar vestibulitis. Ann Dermatol Venereol 2006; 133: 807-8.

[13] Brown CS, Glazer HI, Vogt V, Menkes D, Bachmann G. Subjective and objective outcomes of botulinum toxin type A treatment in vestibulodynia: pilot data. J Reprod Med 2006; 51: 635-41.
[14] Dykstra DD, Presthus J. Botulinum toxin type A for the treatment of provoked vestibulodynia: an open-label, pilot study. J Reprod Med 2006; 51: 467-70.

[15] Romito S, Bottanelli M, Pellegrini M, Vicentini S, Rizzuto N, Bertolasi L. Botulinum toxin for the treatment of genital pain syndromes. Gynecol Obstet Invest 2004; 58: 164-7.

[16] Gunter J, Brewer A, Tawfik O. Botulinum toxin A for vulvodynia: a case report. J Pain 2004; 5: 238-40.

(C) Rodríguez-Cerdeira et al.; Licensee Bentham Open.

This is an open access article distributed under the terms of the Creative Commons Attribution License (http://creativecommons.org/licenses/by/2.5/), which permits unrestrictive use, distribution, and reproduction in any medium, provided the original work is properly cited. 